\title{
Das liturgische Drama von den fünf klugen und den fünf thörichten Jungfrauen.
}

\author{
(Sponsus.)
}

Die Erklärung eines liturgischen Dramas hat vor allem auf den Wortlaut des biblischen Textes zurückzugehen, dessen Inszenierung es ist. Eine genaue Vergleichung von Bibeltext und Drama ist die Grundlage der richtigen Erkenntnis. Das Drama setzt den biblischen Bericht in Aktion.

So wenig diese Wahrheit neu ist, so wenig scheint sie bislang bei der Interpretation des ehrwürdigen Sponsus beachtet worden zu sein.

Ohne die bisherigen Deutungsversuche, die zum Teil sehr gewaltsam und sehr voraussetzungslos mit der Ueberlieferung umgehen, auf ihre Stichhaltigkeit im Einzelnen zu prüfen, teile ich hier mit, was sich mir zwanglos aus den Thatsachen ergiebt. Statt den alten Text zu schulmeistern, suche ich von ihm zu lernen, von der Ueberzeugung erfüllt, dafs derjenige, der ihn im XII. Jahrhundert, leider flüchtig, niederschrieb, etwas vor uns allen voraus hatte: die lebendige Anschauung des liturgischen Dramas.

I.

Die Gegenüberstellung des Evangeliums (Matth. 25, 1-1 2) und des Dramas zeigt zur Evidenz, dafs die achtundvierzig lateinischen Verse für sich allein das lückenlose liturgische Stück bilden. Wie üblich, geben diese lateinischen Verse die crweiterte Umschrcibung der dialogischen Partien des heiligen Textes, während die erzählenden Teile des Evangeliums die Grundlage der Inszenierung bilden und geradezu als die Didaskalien des Dramas betrachtet werden müssen. Das vom Evangelium blofs Erzählte wird gespielt (pantomimisch); das darin Gesprochene wird in der Paraphrase der Verse gesungen.

Das Evangelium ist nicht das Textbuch, wohl aber das Regiebuch des liturgischen Dramas.

Darnach hat der Sponsus folgendes Aussehen:

I. Tunc erit simile regnum calorum decem virginibus, qua sumptis lampadibus suis exierunt in occursum Sponsi.

2. Quinque autem ex eis erant prudentes et quinque fatua.

Zeitschr. E rom. Phil. XXII. 

secum:

3. Qua erant fatua, sumptis Lampadibus suis, non ceperant oleum

4. Prudentes vero ceperant oleum in vasis suis una cum suis lampadibus.

5. Morante autem Sponso, nictarunt omnes ac dormierunt.

6. Media vero nocte clamor ortus est dicentium:

Ecce Sponsus venit, exite in occursum eius!
Adest Sponsus, qui est Christus, vigilate virgines!

Pro adventu cuius gaudent et gaudebunt homines.

Venit enim liberare gentium origines,

Quas per primam sibi matrem subiugarunt dæmones.

5 Hic est Adam, qui secundus per prophetam dicitur,

Per quem scelus primi Adæ a nobis diluitur.

Hic pependit ut cœlesti patriae nos redderet, Ac de parte inimici liberos nos traheret.

Venit Sponsus qui nostrorum scelerum piacula

10 Morte lavit atque crucis sustulit patibula.

7. Tunc surrexerunt omnes illa virgines et adornarunt lampades suas.

Fatuæ:

8. Fatua vero pruden- Nos virgines quæ ad vos venimus, tibus dixerunt: Date nobis ex $\mathrm{Ut}$ ad illas quibus nos credimus, oleo vestro, quia lampades (Ad) vos orare, sorores, cupimus: nostra extinguuntur. Negligenter oleum fudimus. 1

15 Nos comites huius itineris

Et sorores eiusdem generis, Quamvis male contigit miseris Potestis nos reddere superis.

Partimini lumen lampadibus!

20 Piæ sitis insipientibus!

Pulsæ ne nos simus a foribus, Cum vos Sponsus vocet in sedibus.

9. Responderunt autem prudentes illa dicentes: Nequaquam, ne nos sufficiat nobis et vobis. Ite vero po- 25 tius ad illos qui vendunt et ipsa vobis emite!
Prudentes:

Nos precari, precamur, amplius

Desinite, sorores, ocius!

5 Vobis enim nil erit melius

Dare preces pro hoc ulterius.

At ite nunc, ite celeriter,

Ac vendentes rogate dulciter,

Ut oleum vestris lampadibus

30 Dent equidem vobis inertibus.

1 Die Verse 12, 13 und 14 bietet die Hs. in der Reihenfolge: 14, I3, 12. 
10. Cum autem abirent emptum,

$$
\text { [F a tuæ:] }
$$

A, miseræ, nos hic quid facimus?

Vigilare numquid potuimus?

Hunc laborem quem nunc perferimus

Nobis nosmet [ipsæ] contulimus!

35 At det nobis mercator ocius

Quas habeat merces, quas socius.

Oleum nunc quærere venimus,

Negligenter quod nosmet fudimus.

A, miseræ, nos ad quid venimus?

40 Nil est enim illud quod quærimus!

Fatatum est et nos videbimus:

Ad nuptias nunquam intrabimus!

(Modo veniat Sponsus.)

venit Sponsus et qua parate erant introierunt cum eo ad nuptias et clausum est ostium.

I1. Postea vero veniunt et reliqua virgines

dicentes: Domine, domine, Audi, Sponsus, voces plangentium!

aperi nobis!

Aperire fac nobis ostium!

45 Cum sociis ad dulce prandium

Nostræ culpæ præbe remedium.

(Modo veniat Sponsus.)

12. Ipse vero respondens ait: Amen dico vobis, non novi vos.

\section{Christus:}

Amen dico, vos ignosco, nam caretis lumine. Quod qui perdunt, procul pergunt, huius aulæ limine.

(Modo accipiant eas dæmones et præcipitentur in infernum.)

In dieser Form zeigt das Drama gegenüber dem Wortlaut der Bibel eine Abweichung und eine Erweiterung.

Die Frweiterung besteht in der Darstellung des Ganges zu den Händlern. Das Evangelium sagt nichts über den Erfolg dieses Ganges, sondern konstatiert ihn blols mit zwei Worten: abierunt emplum. Das Drama zeigt, seiner Aufgabe zu veranschaulichen gemäls, zwei Händler, die indessen nicht sprechen, sondern augenscheinlich mit Geberden die Jungfrauen abweisen. Es liegt in dem abierunt emptum der Keim einer eigentlichen Szene. Derselbe hat bereits $\mathrm{zu}$ wachsen begonnen. Doch hat er die Hülle des liturgischen Textes noch nicht gänzlich gesprengt, indem von den beiden spielenden Parteien (Fatua und Mercalores) nur die liturgisch legitimierte spricht: die in dem emplum verborgenen Mercatores sind zwar sichtbar geworden, aber noch nicht aus ihrem biblischen Schweigen herausgetreten.

Die Abweichung bezieht sich auf Vers 3-5 des Evangeliums, denen zufolge die Thörichten Oel mitzunehmen vergessen 
haben. Im Drama haben sie ihr Oel vielmehr nachlässig verschüttet (Vers $14 ; 38$ ). Und dies ist augenscheinlich während des Schlafes geschehen, den sie sich selbst zum Vorwurf machen (32).

Der Schlaf der Faluce wird in den Worten des Dramas so nachdrücklich als das Zeichen ihrer Nachlässigkeit und die Ursache ihres Milsgeschicks hervorgehoben, dafs man sich die Prudentes im Gegensatz dazu als die Wachenden vorzustellen veranlafst sieht. Es ist damit ein grundlegender Kontrast in das Spiel hineingetragen, den das Gleichnis des Evangeliums nicht kennt (nictarunt omnes ac dormierunt), den der heilige Text aber mit veranlarst hat, indem er die Lehre des Gleichnisses (Vers 13) in die Worte falst: Vigilate itaque quia neque illum diem neque illam horam scitis qua Filius hominis veniet. In der Aufführung mochte sich die Sache so gestalten, dals die Prudentes beim Rufe: Adest Sponsus ... vigilate virgines! erwachten und sich rüsteten, während die Fatuce sorglos weiter schliefen bis zum Schlufs des Gesanges.

Demnach wird das Spiel etwa so verlaufen sein: Die zehn Jungfrauen treten mit ihren Lampen und Oelkrügen auf und setzen sich, fünf zur Rechten, fünf zur Linken, im Chor. Sie entschlafen alle. Dann hebt der Gesang Adest Sponsus ( 1 - I0) an. Bei den ersten Worten erwachen die Klugen und bereiten ihre Lampen. Die Thörichten schlafen weiter und aus ihren Krügen fliefst das Oel. Endlich schrecken auch sie auf und wollen, wie die Weisen, ihre Lampen bereit machen. Da fehlt ihnen das Oel. Sie nähern sich hierauf im Bittgesang den Klugen (I I-22). Diese weisen sie $a b$ und $z u$ den Händlern (23-30). Die Thörichten jammern über ihr Mifsgeschick (3I-34), nehmen den Weg zu den zwei seitab postierten Händlern $(35-38)$, wo sie aber ebenfalls abgewiesen werden, was sie zu neuen Klagen veranlalst (39-42). Während ihrer Abwesenheit erscheint der Sponsus und führt die Klugen mit sich, etwa in die Sakristei, deren Thür sich schliefst. Die Thörichten kehren zurück und klopfen bittend an $(43-46)$. Der Sponsus erscheint von Neuem unter der Thür und weist sie zurück $(47$ f.). 1

II.

Zum lateinischen Text des liturgischen Dramas gesellt sich mit der Zeit der romanische. ${ }^{2}$

Er hat den Charakter und Zweck einer Glosse (farcimen): er soll dem Laien den Sinn des lateinischen Spiels verdeutlichen.

Diese romanische Glosse bedient sich dreier Formen:

I. Sie formuliert das Redethema in Kehrreime;

2. Sie fügt zur lateinischen Rede die freie lehrhafte Uebersetzung;

1 Dafs die Teufel erscheinen und sie fortschleppen ist dem ältern liturgischen Drama fremd.

2 Ich verweise im Folgenden auf den freilich ungeschickten Abdruck in Bartsch-Horning's Chrestomathie als den verbreitetsten (B.-H.) 
3. Sie erweitert das Spiel und veranschaulicht es über den Rahmen der Liturgie hinaus.

Unser Drama zeigt in der Niederschrift des XII. Jahrhunderts alle drei Formen.

I. Der Refrain, die älteste Art der vulgären dramatischen Glosse, ist im Sponsus für das strophische Mittel- und Hauptstück, die Worte der Jungfrauen, durchgeführt: Dolentas, chailivas! Trop $i$ avel (avem) dormit! Durch diese resümierende Wendung wird nachdrücklich bezeugt, dafs die Fatuce mehr geschlafen haben als die Prudentes und dals das Drama darin ihre Schuld und ihr Unglück sieht. Die Geschichte des liturgischen Dramas erlaubt uns, anzunehmen, dafs es zunächst bei dieser bescheidenen Romanisierung sein Bewenden hatte.

2. Dann wurde die Verdeutlichung der noch unkommentierten Teile, des Anfangs- und des Schlufsgesanges, in Form einer freien romanischen Wiedergabe unternommen und den lateinischen Versen angehängt. ${ }^{1}$ Im Versmals schliefsen sich die beiden Uebersetzungsstücke den strophischen Teilen (Couplets) des lateinischen Dramas an. Die Musik ist in der Handschrift für das Schlu[sstück leider nicht notiert, wohl aber für die Couplets des romanischen Anfangsgesanges. Sie haben eine von den folgenden lateinischen Strophen verschiedene Melodie. Die Uebersetzung ist also musikalisch selbständig (cf. $Z$ frPh. XI, 470). - Für den Geist der freien romanischen Umschreibung der liturgischen Gesänge ist besonders die Schlursrede des Sponsus bezeichnend, die so viel rauher und drastischer ist als der latèinische Wortlaut: erst die Vulgärsprache führt Hölle und Teufel ins liturgische Drama ein.

3. Es liegt in der Natur der Sache, dafs die romanische Glossierung sich endlich jenes dramatischen Keims bemächtigte, der im Geberdenspiel der Mercatores lag. Es wurde die abweisende Haltung der Händler in die Worte zweier romanischer Strophen gefafst (B.-H. Spalte 16). Schon dadurch, dafs die Melodie dieser Strophen nur eine Wiederholung der vorangehenden lateinischen $(23-30)$ ist, erweist sich die Rede der Händler als ein jüngerer Zusatz.

Aus diesem sekundären romanischen Kern konnte sich offenbar mit der Zeit eine vollständig romanische Szene zwischen den Faluce und den Mercalores entwickeln, die dann auch die Romanisierung des Dialogs der Fatuce und der Prudentes mit sich brachte. Von dieser weitern Entwickelung ist uns nur ein Fragment von drei Versen aus der Rede der Prudentes (B.-H. 15, 36 ff.) erhalten. Dasselbe liegt ungeschlacht, wie ein erratischer Block, in dem sonst so ungestörten Flufs der dramatischen Rede. Sei es dafs der ur-

1 Da der Uebersetzer den Engel Gabriel - den Engel der Verkündigung - das sprechen lärst, was das Evangelium als clamor ... dicentium bezeichnet, so legte er wohl die Worte: Adest Sponsus etc. nicht einem Chor, sondern diesem Engel in den Mund. 
sprüngliche Uebersetzer seine Arbeit überhaupt nur eben begonnen hat, sei es dafs die Ungunst der schriftlichen Ueberlieferung die vollendete Arbeit bis auf diese Trümmer zerstört hat: jedenfalls ist von einem ungeschickten Kopisten hier zwischen die lateinische Rede der Falua und die romanische der Mercatores etwas eingefügt worden, was nicht hierher gehört.

Ein moderner Herausgeber des Spoinsus wird sich zu begnügen haben, diese Verse einzuklammern. Dadurch, dafs er sie, wie z. B. Cloetta (Romania XXII, 227), umstellt (zu B.-H. 15, 21), erreicht er zwar eine äufserliche, glatte Lesbarkeit,1 aber er stellt einen Zustand des Textes her, der nie bestanden hat und der sich nicht einmal auf die Autorität eines Kopisten des XII. Jahrh. berufen kann. -

So ist der Sponsus entwickelungsgeschichtlich von besonderem Interesse: er zeigt uns, in der einzigen Niederschrift, die wir besitzen, die drei verschiedenen Formen der Romanisierung des liturgischen Dramas über einander geschoben: den Refrain, die Uebersetzung, die Erweiterung.

III.

Der Sponsus wird von allen Erklärern als Weihnachtsdrama bezeichnet.

Zunächst mag indessen darauf hingewiesen werden, dafs der Wortlaut von Matth. 25, I-12 keine Beziehung zum Mysterium der Inkarnation hat, sondern eschatologischen Inhalts ist.

Als Lectio dienten eschatologische Texte vorzüglich am Schlufs des Kirchenjahrs. Unter den Lutherischen Perikopen erscheint Malth. 25, 1-1 2 am 27. Sonntag nach Trinitatis, d. h. am letzten Sonntag vor der Adventszeit. In der römischen Liturgie aber hat der Text nicht eine solche bestimmte Stelle. Er gehört zu den in communi virginum benutzten Bibelabschnitten und wird also nach Wahl in die gottesdienstliche Feier verschiedener jungfräulicher Heiligen (in natali virginum) eingefügt. So hat Matth. 25, I-12 keinerlei liturgische Beziehung zum Weihnachtsoffizium.

Prüfen wir den lateinischen Text unseres Sponsus, so finden wir allerdings in den einleitenden Septenaren einige Ausdrücke, die an die Weihnachtsfeier gemahnen:

Christus... Pro adventu cuius gaudent et gaudebunt homines... Hic est Adam, qui secundus per propheta m dicitur ...

Aber diese doch recht vage Beziehung hält nicht Stand angesichts des Wortlautes der romanischen Umschreibung: die Rede des Engel Gabriel gipfelt in der Erklärung: $E$ resors es!

Es heifst: Venit en terra - fo net - fo batut - sus ela crot levet ... eu monumen pauset, im Tempus der Vergangenheit, und

1 Die Symmetrie des im Uebrigen so symmetrischen Baues des Ganzen ist nach wie vor zerstört. 
am Schlufs: $E$ resors es! im Tempus der Gegenwart: Christ ist erstanden!

Für den romanischen Uebersetzer ist der Sponsus ein Auferstehungsdrama. Das Stück ist zur Osterfeier gezogen worden, auch wenn es ursprünglich liturgisch zu einer andern Feier gehört haben sollte. 1

Das Mysterium der Fleischwerdung wird nicht, wie im Prophetendrama, als bevorstehend verkündet, sondern als vergangen berichtet. Verkündet wird das Mysterium der Auferstehung.

Dazu erwäge man nun den Zusammenhang der handschriftlichen Ueberlieferung. Es gehen dem Sponsus eine Reihe lateinischer Tropen voraus. Die meisten haben auf das Weihnachtsfest Bezug; einer (Senescente mundano filio) ist eschatologischen Inhalts. Dann folgt, dem Sponsus unmittelbar vorangehend:

Hoc est de mulieribus.

1. "Ubi est Christus meus dominus et filius excelsus? Eamus videre sepulcrum."

2. "Quem quaritis in sepulcro, o christicola?"

3. ["Iesum Nazarenum crucifixum, o calicola."]

4. "Non est hic; surrexit, sicut pradixerat. Ite, nuntiate discipulis eius quia pracedit vos in Galileam."

5. "Vere surrexil dominus de sepulcro, cum gloria. Alleluia."

Der aus den Berichten des Matthæus-, Marcus- und Lucasevangelium zusammengefügte Prosadialog der drei Marien und der Engel, die das leere Grab Jesu bewachen, ist bekanntlich die älteste, in's X. Jahrhundert zurückgehende Form der dramatischen Osterfeier. ${ }^{2}$ Der Kern dieser Grabesszene hat sich dann entwickelt, indem weitere Worte und Szenen aus den Auferstehungstexten angefügt wurden, so der Wettlauf der beiden Apostel (Joh. 20) und die Erscheinung Christi vor Maria Magdalena (ib.) im XII. Jahrhundert.

Eine ähnliche Erweiterung des alten Osterspiels durch eine Erscheinungsszene scheint mir im Sponsus vorzuliegen.

Sein romanischer Wortlaut sowie seine handschriftliche Stellung als Folge der alten Grabesszene geben ihn in gleicher Weise als Osterfeier zu erkennen.

I Solche Verschiebungen kommen vor: so ist der Adam zur Weihndachtsfeier gezogen und mit dem Prophetendrama verbunden worden, obschon der Sündenfall als Lectio dem Sonntag Septuagesima zugewiesen war.

2 Der Text der Handschrift ist einerseits unvollständig, da Satz 3 fehlt und andrerseits gegenüber der ursprünglichen Form durch Satz 1 sowie durch andere dem Ritual entnommene Worte erweitert. (Cf. Lange, Die lateinischen Osterfeiern, München 1887 , SS. 22. $3 \mathrm{I}$ ff. und die zusammenfassende Darstellung Gröber's im Grundrifs II a S. 423.)

H. MoRr. 